\title{
A gestão do conhecimento holística: delineamento teórico conceitual
}

\begin{abstract}
Fábio Corrêa $^{I}$
${ }^{I}$ Centro Universitário Newton Paiva, Belo Horizonte, MG, Brasil. Doutor em Sistemas de Informação e Gestão do Conhecimento. MBA em Engenharia de Software e Governança de Tecnologia da Informação.
\end{abstract}

http://dx.doi.org/10.1590/1981-5344/3542

Introdução: O paradigma holístico é anunciado para a Gestão do Conhecimento há décadas. No entanto, o delineamento teórico acerca desse paradigma para seu ajustamento junto a Gestão do Conhecimento se faz necessário. Isso porque o holismo têm admitido interpretações errôneas e seu uso em conjunto com a Gestão do Conhecimento pode resultar na percepção de que seja, apenas, abordar as empresas em sua completude, como foco no conhecimento.

Objetivo: Este estudo objetivou delinear teoricamente $o$ que consiste o paradigma holístico e o ajustar a Gestão do Conhecimento, anunciando, posteriormente, o conceito de Gestão do Conhecimento holística.

Metodologia: Trata-se de uma pesquisa exploratória, por buscar esclarecer e delinear conceitos e ideias com vistas a municiar problemas pesquisáveis para estudos posteriores.

Resultados: Como resultado a Gestão do Conhecimento holística é delineada teoricamente e conceituada. Isso tende a prover um alicerce para o desenvolvimento de pesquisas que considerem a Gestão do Conhecimento totalitária nas organizações.

Conclusão: Conclui-se que a Gestão do Conhecimento holística é uma proposta que visa abordar as partes pelo todo, considerando que essas partes não devem ser analisadas de forma isolada por haver uma interligação entre essas e, portanto, resulta em recontextualizar essas partes num molde que contemple a totalidade. 
Palavras-chave: Paradigma newtoniano-cartesiano. Paradigma holístico. Gestão do Conhecimento. Gestão do Conhecimento holística.

\section{The holistic knowledge management: theoretical conceptual delineation}

Introduction: The holistic paradigm has been announced for Knowledge Management for decades. However, the theoretical delineation about this paradigm for its adjustment together with Knowledge Management becomes necessary. This is because holism has admitted erroneous interpretations and its use in conjunction with Knowledge Management can result in the perception that it is only to approach companies in their completeness, as a focus on knowledge.

Objective: This study aimed to delineate theoretically what the holistic paradigm consists of and adjust the Knowledge Management later announcing the concept of holistic Knowledge Management.

Methodology: This is an exploratory research, for seeking to clarify and delineate concepts and ideas in order to provide searchable problems for later studies.

Results: As a result, holistic Knowledge Management is conceptually delineated. This tends to provide a foundation for the development of research that considers totalitarian Knowledge Management in organizations.

Conclusion: It is concluded that the holistic Knowledge Management is a proposal that aims to approach the parts for the whole, considering that these parts should not be analyzed in isolation because there is an interconnection between them and, therefore, it results in recontextualizing these parts in a contemplating mold the totality.

Keywords: Newtonian-cartesian paradigm. Holistic paradigm. Knowledge Management. Holistic Knowledge Management.

Recebido em 28.05.2018 Aceito em 04.02.2019 


\section{Introdução}

Ao longo do desenvolvimento de estudos relacionados a Gestão do Conhecimento (GC) diversas abordagens teóricas e práticas foram desenvolvidas. Dentre as teóricas se tem os tipos de conhecimento passíveis de serem geridos, como o declarativo, processual, causa, relacional, básico, avançado e inovador (ZACK, 1999), tácito e explícito (NONAKA; TAKEUCHI, 1997) e implícito (NICKOLS, 2000; GRANT, 2007). Em relação as práticas se destacam os frameworks de GC, propostos para implementar a GC nas organizações (TERRA, 2005; PONS et al., 2014; SALZANO et al., 2016)

Ambas as abordagens convergem para as organizações. A teoria desenvolvida se alia a implementação prática visando gerir o principal ativo das organizações: o conhecimento. Em paralelo estudos tem avaliado modelos de GC e ponderado a necessidade de uma abordagem holística, que apreenda a GC nas organizações de forma totalitária. Essa constatação foi anunciada mediante ao exame total de 270 modelos de GC, avaliados em uma perspectiva longitudinal por Holsapple e Joshi (1999), Rubenstein-Montano et al. (2001), Heisig (2009) e Fteimi (2015).

No entanto, esses estudos não clarificam o que é uma GC holística. Conforme Pierre Weil, ao prefaciar a obra de Crema (2015), interpretações errôneas acerca do termo holismo tem se proliferado. Esse termo ajustado a GC tende a resultar em interpretações que suscitam a ideia de que o holístico para a GC é, apenas, abordar a empresa em sua completude, como foco no conhecimento. Assim, esse estudo tem por objetivo delinear teoricamente o que é o holismo e o ajustar a GC, apresentando uma definição que evidencie o que se assume por GC holística.

Para esse feito, essa pesquisa se subdivide em seções. Primeiramente (subseção 2.1) se torna necessário regressar ao paradigma anterior (e ainda predominante), denominado cartesiano-newtoniano. Mediante ao conceito de que um paradigma consiste em instrumentos metodológicos propostos para abordarem os problemas científicos (KUHN, 1998), o regresso ao paradigma supracitado é fundamental para a compreensão do paradigma holístico, tratado posteriormente (subseção 2.2). Em sequência (subseção 2.3) a distinção entre esses paradigmas é apresentada. Adiante, o ajustamento da GC ao paradigma holístico (seção 3) é exposta e um conceito de GC holístico é apresentado.

\section{Desenvolvimento}

Um paradigma resulta em como as ciências fazem uso de instrumentos científicos metodológicos para abordarem os problemas (KUHN, 1998). Quando os problemas abordados não são solvidos pelo paradigma presente novos instrumentos metodológicos são propostos visando tratar a problemática em estudo. Adiante, esses novos instrumentos tendem a culminar em novas teorias que comporão um novo 
paradigma, ou seja, um novo padrão científico para tratar os problemas não solucionados pelo paradigma anterior.

Sob esse alicerce, para abordar o paradigma holístico se torna necessário regressar ao paradigma predecessor. Isso permite compreender as motivações que resultaram no novo padrão almejado para tratar os problemas científicos. Assim, o paradigma que antecede ao holístico, denominado, paradigma cartesiano-newtoniano, é primeiramente apresentado (subseção 2.1). Em momento seguinte (subseção 2.2), o paradigma holístico é abordado e as distinções entre esses são assinaladas adiante (subseção 2.3), permitindo que se defina os limites teóricos entre ambos. Isso é posto de forma a subsidiar a compreensão do que se denomina por GC holística.

\subsection{O paradigma cartesiano-newtoniano: o reducionismo}

Weil (1991) imputa ao paradigma cartesiano-newtoniano as causas da fragmentação da atualidade e assegura que

Se olharmos em nossa volta [...] seremos obrigados a reconhecer que vivemos numa época caracterizada pela divisão, pelas dissensões, pela violência, pela destruição e pela guerra. (WEIL, 1991, p. 16).

Coimbra (1996), corroborando com Weil (1991), afirma que "Foi o paradigma cartesiano-newtoniano responsável pelo desencadeamento das infindáveis especializações e pela visão mecanicista do mundo" (COIMBRA, 1996, p. 61).

Por esses relatos e pelos registros de Weil (1991), Crema (1991), Vergara (1993), Coimbra (1996), Ferreira (2009) e Crema (2015), dispostos em uma perspectiva longitudinal, é necessário retomar o passado para que seja possível compreender o ambicionado para o futuro. Segundo Ferreira (2009) as contribuições do filósofo René Descartes (1596-1650) foram as que mais influenciaram a sociedade industrial e o mundo moderno.

Esse filósofo introduziu o método cartesiano no qual, a partir de uma dúvida, se busca evidências para sua comprovação ou refutação, por meio da análise, síntese e verificação de cada parte do fenômeno (VERGARA, 1993; FERREIRA, 2009). Descartes acreditava que por meio desse método racional de reflexão, pautado na intuição e dedução, se poderia chegar a verdade. Intuir, para Descartes, era compreender inequivocamente pela luz da razão (racionalidade) e deduzir era promover inferências baseadas em fatos tidos como certos (FERREIRA, 2009).

Crema (2015) expõe a visão de Descartes e sinaliza como o paradigma reducionista se estabelece. Descartes, filósofo, matemático e possuidor de uma mente analítica, repensa a filosofia de sua época e promove uma primeira segmentação, que se estabelece pela árvore de conhecimento, na qual as "raízes constituem a metafísica; o tronco, a física; e os ramos, as ciências derivadas, de modo especial a medicina, a mecânica e a moral" (CREMA, 2015, cap. 2, sem número). Esse processo 
substanciou "os três grandes ramos da ciência atual: as ciências físicas, as ciências biológicas e as ciências humanas, entre as quais a psicologia" (WEIL, 1991, p. 20).

Para Crema (2015) a visão cartesiana opera sob a concepção do homem enquanto máquina, máquina essa que abriga a alma e que possui em seu cerne o pensamento, o que promove o reducionismo do homem em partes que tende a permitir o processo racional pela análise dessas. Desse ponto, emerge a concepção mecanicista de que o homem, enquanto máquina, habita um universo, também máquina, governado por leis matemáticas perfeitas. Portanto, o que se tem é a fragmentação da natureza científica e do homem, anteriormente visto como uma unidade totalitária, para uma visão puramente racionalista-mecanicistareducionista (CREMA, 2015).

Isaac Newton (1642-1727), físico, matemático e astrônomo, contribuiu para a construção de uma visão mais racional do mundo (FERREIRA, 2009). Seus diversos feitos sobre o entendimento do universo (VERGARA, 1993), como a lei da gravidade, lei da atração de corpos e decomposição da luz solar no espectro, o denominaram fundador da mecânica clássica (FERREIRA, 2009). Essa conotação faz referência a relação de causa e efeito (MACIEL; SILVA, 2008) na qual as leis de Newton coroaram o reducionismo proposto por Descartes (PEREIRA, 2002). Newton, adepto a mecanização e a matematização, exprimiu que

Oxalá pudéssemos também derivar os outros fenômenos da natureza dos princípios mecânicos, por meio do mesmo gênero de argumentos, porque muitas razões que me levam a suspeitar que todos esses fenômenos podem depender de certas forças pelas quais as partículas dos corpos, por causas ainda desconhecidas, ou se impelem mutuamente, juntando-se segundo figuras regulares, ou são repelidas e retrocedem umas em relação as outras. Ignorando essas forças, os filósofos tentaram em vão até agora a pesquisa da natureza. (NEWTON, 1974 apud CREMA, 2015, cap. 2, sem número)

Além de Descartes e Newton outros nomes como Francis Bacon (1561-1626) e Galileu Galilei (1564-1642) também contribuíram para esse modelo de ciência (WEIL, 1991; CREMA, 1991; CREMA, 2015) que, em síntese, se fundamenta na lógica de Descartes de divisão do fenômeno em menores partes para que se possa compreender essas partes isoladamente, levando a compreensão do fenômeno em sua totalidade. Newton, por uma ótica de causa e efeito, determina que cada fenômeno possui causas e efeitos previsíveis, o que permite prever o futuro com clareza (CAPRA, 2000; MACIEL; SILVA, 2008; CREMA, 2015). Em suma

Newton e Descartes eram defensores contumazes da previsibilidade, certeza, estabilidade, ordem, rigidez, linearidade, ou raciocínio sequencial, razão e objetividade, preocupação com as partes, problemas entendidos isoladamente. (PEREIRA, 2002, p. 10)

Coimbra (1996) denomina o modelo científico de Descartes e Newton como um paradigma cartesiano-newtoniano, respectivamente 
atrelado aos nomes dos pensadores. Também rotulado como "reducionista, [...], mecanicista, positivista, ou ainda determinista" (MACIEL; SILVA, 2008, p. 55), esse paradigma moldou a forma de se fazer ciência e se tornou um padrão clássico que triunfa até os dias atuais, pois influenciou diversas áreas da ciência e da sociedade (WEIL, 1991; PEREIRA, 2002; CREMA, 2015).

No campo da Administração, Ferreira (2009) manifesta que o reducionismo está presente na abordagem mecânica da Administração, fundamentada em Taylor e Fayol. Na sociedade está presente na educação (BEHRENS, 1999; FLACH; BEHRENS, 2008), política (WEIL, 2001) e em diversos outros contextos (CREMA, 2015). Pois bem, e como isso reflete nos dias atuais? Alguns exemplos são destacados para que seja possível visualizar as consequências desse paradigma científico.

A Administração Científica se fundamenta na aplicação de métodos científicos na administração. Frederick Winslow Taylor (1856-1915), engenheiro e economista, estabeleceu a aplicação da ciência na administração por meio de estudos, como tempos e movimentos e a organização racional do trabalho, para elevar a eficiência e a produtividade da organização (SILVA, 2013).

Silva (2013, p. 111) pondera que "Muitos dos métodos de Taylor não eram em si originais. A originalidade estava na aplicação desses métodos com a visão do engenheiro". O estudo dos tempos e movimentos promoveu a racionalização do trabalho dos operários dissolvendo cada atividade em movimentos elementares e, com efeito

Taylor reduziu o homem a gestos e movimentos, sem capacidade de desenvolver atividades mentais, que, depois de uma aprendizagem rápida, funcionava como uma máquina. O homem, para Taylor, podia ser programado, sem possibilidade de alteração, em função da experiência, das condicionantes ambientais, técnicas e organizacionais. (ANDRADE; AMBONI, 2017, cap. 4, sem número, sublinho do autor).

Enquanto o sistema de Taylor visava a execução das atividades em um tempo padronizado por movimentos prescritos, no sistema de Henry Ford (1863-1947) os movimentos das pessoas eram ritmados pela velocidade da esteira no processo de produção. A máxima conferida por esse segundo é que o homem não dirige o trabalho, mas sim o contrário, ou seja, as coisas devem se manter em movimento para que o trabalho vá até o homem e esse o faça no ritmo imposto (SILVA, 2013).

Ambos sistemas de Administração - Taylorista e Fordista - se dão pela racionalização do homem e das atividades, fruto das influencias científicas de Descartes e Newton, e se distinguem pelos movimentos.

Aí está a principal diferença dos dois sistemas de administração. Taylor manda executar movimentos sob rígido controle e Ford manda adaptar movimentos tão comodamente quanto possível ao ritmo de produção, às aptidões e à vontade. Taylor se preocupou mais com o estudo do tempo perdido pelo homem e pela máquina; 
Ford procurou suprimir o tempo-perdido pela matéria-prima, com o trabalho contínuo. (SILVA, 2013, p. 122).

Assim, o paradigma cartesiano-newtoniano promoveu, no campo da Administração, a redução do homem em movimentos e o posicionou sob a perspectiva de uma máquina (FERREIRA, 2009), tornando as pessoas especialistas em movimentos (atividades) específicos (MACIEL; SILVA, 2008). Entretanto, conforme Pereira (2002) esse reducionismo não compete aos dias atuais, pois o homem não é uma máquina; esse possui emoções que o acompanham, tanto no contexto pessoal como no profissional. Todavia, não se pode negar os avanços decorrentes desse paradigma para o setor automobilístico e para a Administração em si (ANDRADE; AMBONI, 2017).

No campo científico o percurso galgado ao longo dos anos delineou a fragmentação da ciência em disciplinas e orientou a especialização dos saberes (ALVARENGA; SOMMERMAN; ALVAREZ, 2005; SOMMERMAN, 2005). Um breve olhar sobre a própria estrutura desse artigo, fragmentada em capítulos e seções, demonstra o quão imbricado o reducionismo está no processo científico. Do mesmo modo, no campo educacional a compartimentalização das disciplinas é fruto de um processo reducionista, o que para Weil (2001) torna as universidades verdadeiras torres de Babel. Os conteúdos são expostos de forma segmentada e, conforme Behrens (1999).

O pensamento newtoniano-cartesiano propôs a fragmentação do todo e por consequência as escolas repartiram o conhecimento em áreas, as áreas em cursos, os cursos em disciplinas, as disciplinas em especificidades. A repartição foi tão contundente que levou os professores a realizarem um trabalho docente completamente isolados em suas salas de aula. (BEHRENS, 1999, p. 384)

No campo da Computação, seccionado em hardware e software, apresenta um exemplo claro da abordagem reducionista. Além da referida distinção entre o físico e virtual, os opostos binários 0 e 1 , a modularização dos códigos e os algoritmos assumem relação direta com a perspectiva de reducionista de fragmentação, resultante do método analítico de Descartes e Newton, fundado em dividir para conquistar (CREMA, 1991).

A modularização, proposta pela programação estruturada, consiste em atacar o problema e dividi-lo em partes (tarefas) para melhor desenvolvimento da solução (FARRER et al., 2009). O algoritmo de ordenação MergeSort resulta na abordagem de dividir para conquistar e promove, essencialmente, a divisão de um problema em subproblemas menores para posterior resolução destes de forma a combiná-los para atingir o objetivo de solução do problema original (ZIVIANI; 2014).

Esse breve recorte histórico exalta as seguintes reflexões. Primeiramente, os avanços da humanidade foram e são orientados por uma forma de pensar e abordar os problemas de forma fragmentada, fundamentado no paradigma cartesiano-newtoniano. Por ser um paradigma reinante a milênios esse está imbricado na cultura (MACIEL; 
SILVA, 2008) e no contexto empresarial pode resultar, ainda neste século, num comportamento que reduz o homem a uma abordagem mecânica.

Por essa abordagem mecanicista o homem tende a ser tratado como uma máquina sem emoções (PEREIRA, 2002) e que não contribui com seu potencial cognitivo (ANDRADE; AMBONI, 2017), resquício esse do sistema Taylorista e Fordista. No âmbito social, esse paradigma contribui para uma sociedade caótica que tenta resolver os problemas, sejam políticos ou sociais, por uma ótica ainda fragmentada (WEIL, 1991; CREMA, 2015).

Em segundo momento, embora os pontos supracitados sejam alarmantes e possam resultar na percepção de que o reducionismo é somente nocivo, isso não quer dizer que sua adoção tenha sido um erro. Esse paradigma permitiu avanços tecnológicos (VERGARA, 1993), como o lançamento do Sputnik, em 1957 (CREMA, 2015), a chegada do homem à lua (PEREIRA, 2002) e promoveu a evolução do pensamento humano (FLACH; BEHRENS, 2008).

No entanto, o que é evidenciado por Weil (2001), Flach e Behrens (2008), Crema (2015), dentre tantos outros estudiosos, é que esse paradigma não é mais suficiente para contemplar a realidade vigente, ou seja, se tornou ultrapassado, tanto para a sociedade quanto para as empresas, carecendo de ser recontextualizado nos moldes de uma abordagem que não mais fragmente a realidade (PEREIRA, 2002; FLACH; BEHRENS, 2008).

Essa reflexão se justifica pelo fato de que, em verdade, o que se têm é um mundo mais complicado em comparação ao que se tinha no passado, na época de Descartes, Newton, Bacon e Galileu, dentre outros pensadores. Portanto, o que se assume é a necessidade de uma mudança de paradigma para contemplar a complexidade presente nos dias atuais.

Essa necessidade é posta por Weil (2001), Pereira (2002), Maciel e Silva (2008), Flach e Behrens (2008) e Capra (2000) e Crema (2015), para citar alguns, pela incapacidade de tratar a realidade atual e futura pela perspectiva cartesiana-newtoniana, na qual se determina que cada fenômeno possui causa e efeitos previsíveis, o que permite prever o futuro com clareza. Em observância a Figura 1 essa previsão não mais se aplica.

Figura 1 - Evolução do processo e interpretação do desenvolvimento social: da ordem para a perplexidade 


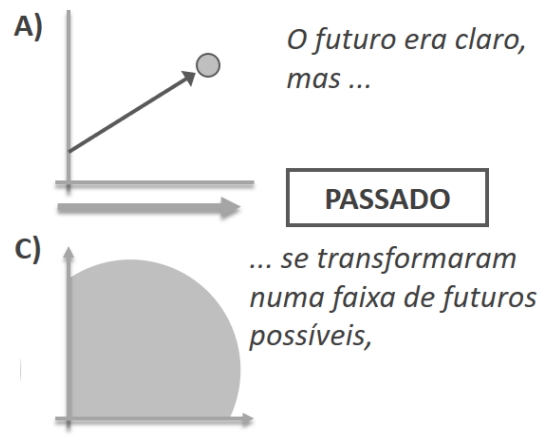

B)

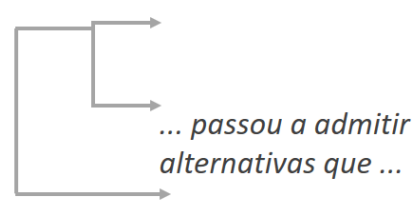

D)

até que chegamos à

imprevisibilidade total.

MOMENTO ATUAL/FUTURO

Fonte: Pereira (2002, p. 11).

Enquanto no momento A o futuro era claro e previsível, tempo esse dos pensadores que moldaram o reducionismo, no momento $B$ passou-se a admitir mais alternativas para o futuro. Por conseguinte, em $\mathrm{C}$ o mundo se torna mais complicado e a previsibilidade assume uma faixa de possíveis futuros, até que chegamos ao cenário caótico e complexo, no qual o momento atual e o futuro são imprevisíveis (PEREIRA, 2002). Portanto, a necessidade de um novo paradigma se faz presente para que se possa tratar a totalidade, a imprevisibilidade do momento atual e vindouro, sendo esse paradigma abordado na seção seguinte.

O paradigma holístico: a totalidade

Uma vez que o paradigma cartesiano-newtoniano, que reduz os fenômenos em partes para compreender o todo, se tornou insuficiente para tratar os problemas atuais e do futuro (WEIL, 1991; CAPRA, 2000; PEREIRA, 2002; MACIEL; SILVA, 2008; FLACH; BEHRENS, 2008; CREMA, 2015), o que se almeja como solução é uma abordagem que não mais fragmente os fenômenos, mas sim os contemplem em sua totalidade, 0 que demanda novos métodos. Assim, emerge o paradigma holístico que, em verdade, é um paradoxo entre os avanços científicos e a situação atual que culminou na complexidade inerente ao mundo contemporâneo.

O termo holístico vem do grego hólus e diz respeito ao todo, inteiro, completo e integro. Tem suas bases na filosofia, que remonta à época de Heráclito (535-475 a.C.), repercutindo entre filósofos e teóricos dos séculos XVII e XVIII, quando se escrevia sobre a conexão entre o homem, a natureza e a vida (MACIEL; SILVA, 2008), mas ganhou um conceito organicista pela publicação Holism and evolution do general sul-africano e filósofo Ian Christian Smuts, datada de 1926 (WEIL, 1991; CREMA, 1991; VERGARA, 1993; PEREIRA, 2002, MACIEL; SILVA, 2008; CREMA, 2015).

Desde então o termo vem ganhando notoriedade; entretanto, conforme Pierre Weil, ao prefaciar a obra de Crema (2015), interpretações errôneas acerca desse termo Têm proliferado e todo esforço para clarear seu significado é bem-vindo. Nesse estudo não se pretende buscar uma definição finalística para o holismo, mas sim o clarificar no contexto de um novo paradigma para, posteriormente, o posicionar no âmbito da GC, sendo, assim, necessário delimitar o escopo desse paradigma. 
Em apreço a obra supracitada de Ian Christian Smuts, Weil (1991) assinala que "Toda a obra de Smuts tende a restabelecer a unidade fundamental subjacente à matéria, à vida e à mente" (WEIL, 1991, 21) o que, em outros termos, condiz com o reestabelecimento da unidade totalitária, fragmentada pelo reducionismo. Do mesmo modo, Vergara (1993, p. 9) demarca que o "mecanicismo e holismo são uma questão de grau; o primeiro é considerado por Smuts como o estágio inicial do segundo. O universo é holístico", ou seja, Smuts não nega o reducionismo, mas o posiciona como um elemento de uma estrutura mais ampla, o hólus.

Para Vergara (1993) o paradigma holístico consiste em um movimento de ideias e não prevê a exclusão do paradigma cartesianonewtoniano; em verdade, busca a complementação da teoria reducionista (CREMA, 1991) que, para Pereira (2002) resulta em recontextualizar seus elementos num molde que contemple a totalidade. Isso porque o homem, por esse paradigma, é um ser indivisível e, como tal, para ser interpretado não pode ser fracionado em menores partes (CREMA, 1991; PEREIRA, 2002).

Uma vez que o modelo reducionista está presente até os dias atuais, mudá-lo é algo tão profundo que tende a ser um processo lento. Logo, conforme Vergara (1993), se admite que o paradigma holístico seja, inicialmente, um movimento de ideias para que, posteriormente, possa ser absorvido e se tornar o novo paradigma reinante, visando atender aos problemas atuais e futuros do mundo em todos os seus âmbitos. Assim, é sobre a perspectiva científica, de tratamento de um fenômeno, que ocorre a dialética entre os dois paradigmas.

Enquanto o paradigma cartesiano-newtoniano divide o todo para que se possa analisar e compreender suas partes de forma a subsidiar o entendimento do fenômeno (WEIL, 1991), o paradigma holístico compreende o todo como um fenômeno totalitário, pois as partes - se admite a redução - se interligam e dividi-las resulta em mutilar o fenômeno e perder tais integrações, não sendo possível analisa-lo em sua completude ou mesmo regressar ao todo para seu entendimento após sua divisão (CAPRA, 2000). Por essa dialética Pereira (2002) esclarece:

Nesse momento, emerge a visão holística de que o todo é mais importante do que as partes e de que, em nenhum instante, o todo pode ser interpretado dividido em partes menores, pois cada parte formará um novo todo.

Por isso a visão holística defende que os elementos não podem ser isolados do seu meio para serem estudados, porquanto há uma interligação entre todos os elementos. (PEREIRA, 2002, p. 12)

Visto como emergencial para a tratativa dos problemas modernos 0 paradigma holístico, também denominado visão holística ou abordagem holística (PEREIRA, 2002), passa a assumir perspectivas que se fundem a outras teorias, como a Teoria Geral dos Sistemas (TGS), Sistemas Adaptativos Complexos (SAC) e Teoria da Complexidade. Nessa pesquisa serão contemplados visando distingui-los quanto a abordagem holística, 
permitindo sua clarificação de forma a subsidiar o que se pretende por essa abordagem no âmbito da GC.

A TGS, proposta em 1937 pelo biólogo alemão Ludwing von Bertalanfy (PEREIRA, 2002), assume três propriedades: 1) o comportamento de cada membro do conjunto afeta o comportamento de todo o conjunto; 2) as propriedades e comportamento de cada membro influencia o todo e é influenciada pelas propriedades e comportamento de pelo menos um membro; e 3 ) todos os subgrupos inseridos no conjunto possuem as propriedades anteriores (BERTALANFFY, 1972).

A exemplo, os órgãos do corpo humano influenciam no funcionamento do sistema humano como um todo (1), bem como o comportamento do coração é influenciado pelo comportamento do pulmão e influencia os demais órgãos (2) e os subsistemas nervoso e respiratório interagem e afetam a totalidade compreendida pelo sistema humano (3).

Para Pereira (2002) a TGS, também denominada por esse como visão sistêmica ou abordagem sistêmica, se ajusta ao paradigma holístico como um primeiro nível para operacionalização do hólus, uma vez que os sistemas da TGS se influenciam mutuamente. Conforme Vergara (1993), o mecanicismo é um estágio inicial do holismo. Assim, se pode inferir que o holismo não somente assume a fragmentação das partes como abarca a TGS, que também assume a redução do todo em partes.

Por primeiro nível, Pereira (2002) assume que é estabelecida uma perspectiva de completude entre essa teoria e o paradigma holístico, expressa da seguinte maneira: "um fenômeno que está sendo interpretado de maneira holística também é um sistema; no entanto, nem todo sistema é consubstanciado em uma visão holística" (PEREIRA, 2002, p. 13), resultando na seguinte esquematização.

Figura 2 - Síntese da visão
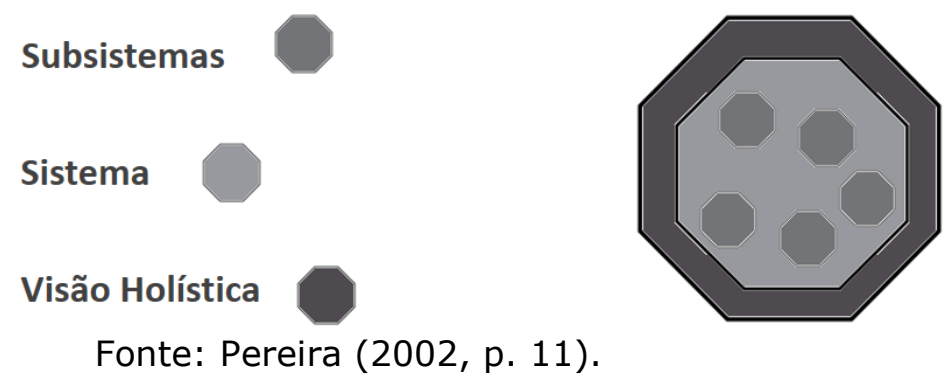

Assim, os elementos (reducionismo), representados por subsistemas (partes), influenciam o sistema como um todo e esse conjunto compõe o paradigma holístico, que visualiza o todo sem isolar as partes, ou seja, não afasta as partes do conjunto para que as influencias entre esses subsistemas e o sistema sejam mantidas. Para Santos, Polosi e Oliveira (2012) a TGS é sintetizada como um todo inter-relacionado que se organiza em partes, mas essa teoria não se esquiva de críticas.

A TGS prima pelo equilíbrio do sistema e "já que um sistema é um todo que se autorregula, todo o conflito que ocorre dentro do sistema é, portanto, regulável" (SANTOS; POLOSI; OLIVEIRA, 2012, p. 60), mas na 
prática, conforme esses pesquisadores, esse equilíbrio não acontece. No contexto organizacional, no qual se estabelece relações sociais, culturais, políticas, econômicas e relações de poder, a autorregulação desse supra sistema organizacional tende ao não atingimento do referido equilíbrio. Para Santos, Polosi e Oliveira (2012) a estabilidade, equilíbrio e a linearidade é o que menos ocorre no mundo, o que fragiliza a TGS.

Essa não linearidade, estabilidade e equilíbrio é comprovada, segundo Santos, Polosi e Oliveira (2012), pela descoberta dos sistemas complexos. Especificamente, sob a base da TGS e dos sistemas complexos se estabelece os Sistemas Adaptativos Complexos (SACs). Como um sistema - TGS - pode ser compreendido como "um grupo de elementos inter-relacionados de modo a compor uma unidade ou totalidade" (PICKERING, 2012, p. 518) os SACs podem ser percebidos como abstração da TGS que admitem os termos adaptativo e complexo.

Adaptativo consiste na capacidade do sistema de se adaptar as mudanças decorrentes do ambiente (PICKERING, 2012) e, por complexo, se resgata Morin $(2005,2005 a)$ ao aludir que complexo é aquilo que é tecido junto, intricado e entrecruzado. Nessa perspectiva, abordar o todo pela secção de suas partes (reducionismo) infere na perda de características do sistema, o que implica em reconhecer a diversidade e as inúmeras interações entre as partes (SILVA; REBELO, 2007), conferindo complexidade na tratativa do todo.

$\mathrm{Na}$ teoria dos SACs a capacidade de adaptação a mudanças ambientais é realizada por meio dos agentes adaptativos existentes no sistema, que seguem um conjunto de regras (STACEY, 1996) para sua melhoria comportamental e do sistema como um todo. Assim, para considerar um agente enquanto adaptativo "suas ações devem agregar valor ao sistema ao longo do tempo" (SILVA; REBELO, 2007, p. 3).

No contexto organizacional, seria reconhecer as pessoas como agentes que se auto organizam e adaptam as mutações do ambiente (MCELROY, 2002). Portanto, o complexo é considerar as interações entre os diversos agentes (o todo) e as características provenientes de tais interações, nas quais os agentes afetam uns aos outros e o próprio ambiente (sistema).

Neste momento, se pode inferir que os SACs se ajustam a TGS assim como essa segunda se ajusta ao paradigma holístico, o que permite visualizar o SACs como uma teoria abarcada pela síntese da visão holística, expressa por Pereira (2002) (reveja a Figura 2). Entretanto, os SACs abrigam o termo complexo que, por sua vez, constitui o cerne da Teoria da Complexidade, expressa por Morin (2005, 2005a), que resgata 0 reducionismo e o holismo.

Morin (2005a) vislumbra os diversos elementos de um sistema e o sistema como um todo por uma ótica na qual tudo se entrelaça e constitui uma complexidade que vai além dos elementos ou do sistema, mas abriga ambos ao mesmo tempo e juntos, caracterizando o todo integralmente. Embora seja complicado e também complexo abordar a complexidade, Morin $(2005,2005 a)$ a trata de uma forma que pode ser sintetizada como: a complexidade visa abordar a completude em si, sem fazer uso do 
reducionismo. Sem fazer uso do reducionismo é não fracionar o todo em partes para que se tenha, de fato, o que se denomina completo e que demonstre a complexidade.

Acontece que o problema da complexidade não é o da completude, mas o da incompletude do conhecimento. Num sentido, o pensamento complexo tenta dar conta daquilo que os tipos de pensamento mutilante se desfaz, excluindo o que eu chamo de simplificadores e por isso ele luta, não contra a incompletude, mas contra a mutilação. Por exemplo, se tentamos pensar no fato de que somos seres ao mesmo tempo físicos, biológicos, sociais, culturais, psíquicos e espirituais, é evidente que a complexidade é aquilo que tenta conceber a articulação, a identidade e a diferença de todos esses aspectos, enquanto o pensamento simplificante separa esses diferentes aspectos, ou unifica-os por uma redução mutilante. Portanto, nesse sentido, é evidente que a ambição da complexidade é prestar contas das articulações despedaçadas pelos cortes entre disciplinas, entre categorias cognitivas e entre tipos de conhecimento. (MORIN, 2005a, p. 176-177)

Por essa ótica, a Teoria da Complexidade se apresenta como um resgate da completude em essência, o que a distingue dos sistemas (TGS e SACs) e do holismo, que considera as partes como constituintes de um sistema (MORIN, 2005a). Segundo Morin (2005a) um sistema complexo compreende o todo pelas partes, o que apresenta uma orientação ao reducionismo. Por outro lado, o holismo compreende as partes pelo todo movimento contrário - o que ainda exprime uma forma simplificadora. Em outras palavras

Isso quer dizer que não podemos mais considerar um sistema complexo segundo a alternativa do reducionismo (que quer compreender o todo partindo só das qualidades das partes) ou do "holismo", que não é menos simplificador e que negligencia as partes para compreender o todo. [...] Isso significa que abandonamos um tipo de expücação linear por um tipo de expücação em movimento, circular, onde vamos das partes para 0 todo, do todo para as partes, para tentar compreender um fenômeno. (MORIN, 2005a, p. 181)

O pensamento complexo, portanto, consiste em uma forma de abordar a completude, a totalidade (MORIN, 2005, 2005a). Mariotti (2004) demonstra como Morin assume o pensamento complexo: "De modo geral, sua proposta [de Morin] é a complementaridade e a transacionalidade entre as concepções linear (reducionista) e "holística" (sistêmica)" (MARIOTTI, 2004). Por essa ótica Mariotti (2004) corrobora com Pereira (2002) ao assinalar o pensamento holístico como abrangendo o sistêmico, ou TGS. O que distingue o pensamento complexo, em relação aos demais, são os princípios da emergência, imposição e a complexidade inerente ao todo não fracionado.

O princípio da emergência ressalta que "o todo é superior à soma das partes" e o da imposição diz que "que o todo é inferior à soma de suas partes" (MARIOTTI, 2004, p. 61, sublinho do autor). Quanto ao 
princípio da emergência, Mariotti (2004) o exemplifica pela reunião de pessoas na qual surge novas ideias que não surgiriam sem o diálogo entre esses indivíduos, assim novas propriedades emergem. Quanto ao princípio da imposição é utilizado a analogia de um coral, no qual os participantes têm de restringir suas potencialidades (voz) ao que o todo (coral) exige, ou seja, as potencialidades das partes (vozes dos indivíduos) se diluem no sistema (coral) (MARIOTTI, 2004).

Em ambos os princípios ocorre a repressão, restrição ou inibição de uma parte em relação a outra - subsistema versus sistema - além da hierarquização, na qual um sistema se estabelece como um subsistema de outro maior e também possui sistemas menores em sua composição (MARIOTTI, 2004), o que remete esses princípios a TGS (reveja a Figura 2). Entretanto, no pensamento complexo "um sistema é mais e menos do que aquilo que poderíamos chamar de soma de suas partes" (MORIN, $2005 a$, p. 180, sublinho do autor), pois ambos os princípios ocorrem juntos e, conforme Morin (2005a, p. 181) "podemos dizer que não só a parte está no todo, mas também que o todo está na parte". Portanto,

[...] complexas é o que está junto; é o tecido formado por diferentes fios que se transformaram numa só coisa. Isto é, tudo isso se entrecruza, tudo se entrelaça para formar a unidade da complexidade; porém, a unidade do complexus não destrói a variedade e a diversidade das complexidades que o teceram. (MORIN, 2005a, p. 188, itálico original)

Essa relação de recursão, na qual a parte está no todo e o todo está na parte, é esclarecida por Morin (2005a) ao exemplificar que cada célula genética do indivíduo contém a totalidade das informações do corpo, a sociedade está presente na mente do indivíduo que, ao mesmo tempo, cria essa sociedade por meio do convívio social. Em outros termos, "nós produzimos a sociedade que nos produz" (MORIN, 2005a, p. 190). Destarte, a complexidade é algo entrelaçado que constitui um só todo e exprime o que Morin estabelece como completude, o resgate da unidade, do uno. As perspectivas da TGS, holística e da complexidade podem ser assim distinguidas.

Quadro 1 - Distinção entre a visão sistêmica, holística e complexa

\begin{tabular}{l|l|l|l|l}
\hline Perspectiva & Direcionamento & Síntese & $\begin{array}{l}\text { Composição } \\
\text { hierárquica }\end{array}$ & $\begin{array}{l}\text { Paradigma } \\
\text { relacionado }\end{array}$ \\
\hline $\begin{array}{l}\text { Sistêmica } \\
\text { (TGS) }\end{array}$ & $\begin{array}{l}\text { Luta contra a } \\
\text { fragmentação }\end{array}$ & $\begin{array}{l}\text { Das partes para o } \\
\text { todo }\end{array}$ & $\begin{array}{l}\text { Sistema e } \\
\text { subsistemas }\end{array}$ & $\begin{array}{l}\text { Tendência } \\
\text { reducionista } \\
\text { original }\end{array}$ \\
\hline Holística & $\begin{array}{l}\text { Luta contra a } \\
\text { fragmentação }\end{array}$ & $\begin{array}{l}\text { Do todo para as } \\
\text { partes }\end{array}$ & $\begin{array}{l}\text { Supra sistema } \\
\text { sobre o sistema }\end{array}$ & $\begin{array}{l}\text { Tendência } \\
\text { reducionista } \\
\text { inversa }\end{array}$ \\
\hline Complexidade & $\begin{array}{l}\text { Regressa para } \\
\text { antes da } \\
\text { fragmentação }\end{array}$ & $\begin{array}{l}\text { Do todo pelas partes } \\
\text { e das partes pelo } \\
\text { todo, uma unidade }\end{array}$ & Não hierárquica & $\begin{array}{l}\text { Não } \\
\text { reducionista }\end{array}$ \\
\hline
\end{tabular}

Fonte: Próprio autor.

O Quadro 1 consolida pontos que distinguem as três visões e se baseia no discurso apresentado até este momento. O direcionamento 
(segunda coluna do Quadro 1) corresponde ao embate de cada perspectiva. Morin (2005a) destaca que o pensamento complexo busca resgatar a completude antes da fragmentação para, assim, considerar o completo em essência, ou seja,

[complexidade] tenta dar conta daquilo que os tipos de pensamento mutilante se desfaz, excluindo o que eu chamo de simplificadores e por isso ele [sistêmico e holístico]] luta, não contra a incompletude, mas contra a mutilação. (MORIN, 2005a, p. 176).

Uma vez o pensamento complexo visa regressar para antes da fragmentação, ou mutilação como diz Morin (2005a), esse se estabelece pelo não relacionamento com o reducionismo (quinta coluna do Quadro 1). Já a perspectiva sistêmica considera as partes (PEREIRA, 2002) assim como a holística, que não exclui o paradigma cartesiano-newtoniano e busca a complementariedade do reducionismo (VERGARA, 1993). Conforme Pereira (2002) o holismo visa recontextualizar seus elementos (partes) num molde que contemple a totalidade e, portanto, a TGS, assim como o holismo, lutam contra a mutilação do reducionismo (MORIN, 2005a).

O sentido (quinta coluna do Quadro 1 ), original ou inverso, é exposto por Morin (2005a) ao relatar que

abandonamos um tipo de expücação linear [sistêmica] por um tipo de expücação em movimento, circular [holismo], onde vamos das partes para o todo, do todo para as partes, para tentar compreender um fenômeno. (MORIN, 2005a, p. 181).

Portanto, o paradigma relacionado tende a ser original - das partes para o todo -, no caso da visão sistêmica, e inverso - do todo para as partes -, no caso da holística. Esse sentido também subsidia a síntese (terceira coluna do Quadro 1) da visão sistêmica e holística, as distinguindo da complexa, pois essa considera todas as partes e o todo como uma unidade antes da fragmentação.

A relação de hierarquização (terceira coluna do Quadro 1) corresponde a existência de um sistema sobre o outro no qual, para Mariotti (2004), um sistema se estabelece como um subsistema de outro maior e também possui sistemas menores em sua composição. Isso ocorre na perspectiva sistêmica e holística, como exposto no Pereira (2002) (reveja a Figura 2), mas não ocorre no complexo, pois nesse "podemos dizer que não só a parte está no todo, mas também que o todo está na parte" (MORIN, 2005a, p. 181).

Assim, se caracteriza o paradigma holístico como um movimento de ideias (VERGARA, 1993) que apregoa a análise do fenômeno em sua completude (CAPRA, 2000) e que reconhece as partes, fragmentadas pelo reducionismo, como existentes no todo (WEIL, 2001), mas defende que essas não devem ser analisadas de forma isolada (PEREIRA, 2002). Ao reconhecer os contributos do paradigma cartesiano-newtoniano (VERGARA, 1993; WEIL, 2001) o paradigma holístico admite que as partes devem ser analisadas cientificamente, entretanto considerando o todo e o 
todo deve ser analisado considerando as partes e não como feito no passado, de forma disjunta.

Destarte, essa pesquisa entende o paradigma holístico conforme exposto anteriormente. Esse assume a presença do reducionismo (VERGARA, 1993; PEREIRA, 2002) e luta contra a fragmentação (MARIOTTI, 2004; MORIN, 2005a) inerente ao modelo cartesianonewtoniano. Ademais, se orienta do todo sobre as partes (MORIN, 2005a) e assume a hierarquia entre os sistemas (PEREIRA, 2004). Essa caracterização é assumida como um pilar para a ambientação do paradigma holístico na GC (seção 3 dessa pesquisa).

\subsection{Distinção entre reducionismo e holismo}

As seções anteriores delinearam os paradigmas cartesianonewtoniano (seção 2.1) e o holístico (seção 2.2). Entretanto, mediante as sutilezas que os distinguem e pela menção da Teoria da Complexidade, torna-se relevante demarcar essas abordagens de forma a evidenciar a abrangência dessas. Essa demarcação, embora disposta por uma perspectiva elevada, tem por intento consolidar as seções anteriores para que seja delineada a abordagem a ser considerada nessa pesquisa. Destarte, a Figura 3 exprime tais visões.

Figura 3 - Distinções entre as visões reducionista, holística e complexa

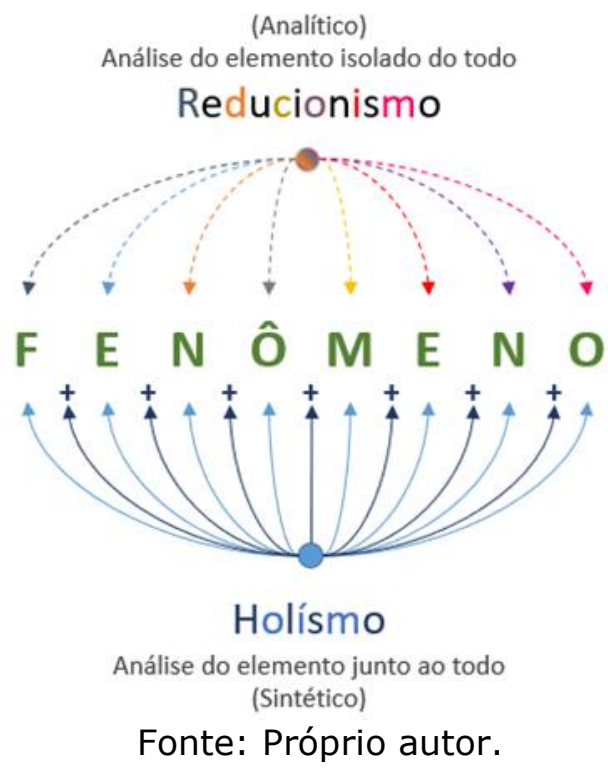

Considerando o "FENÔMENO" como sendo o todo, um determinado fato, evento, ou objeto sucumbido ao estudo científico, cada abordagem o analisa por uma vertente. Por um lado, o reducionismo, ou paradigma cartesiano-newtoniano, analisa esse todo o fraccionando em partes e, cada parte, é analisada de forma isolada do todo (CREMA, 1991; VERGARA, 1993; PEREIRA, 2002; FERREIRA, 2009). Tais partes são vistas como máquinas e as análises são regidas por princípios matemáticos orientados pela razão, se revelando como uma abordagem racionalistamecanicista-reducionista (CREMA, 2015). 
Após a compreensão dessas partes, a soma de seus resultados revela o que constitui o todo, ou seja, o todo é resultado da soma das partes analisadas isoladamente (MARIOTTI, 2004; MORIN, 2005; MORIN, 2005a). As consequências desse processo fragmentador é a perda das interações entre as partes, pois ao analisá-las de forma isolada do todo suas conexões são mutiladas (MORIN, 2005a) e esse processo de simplificação acarreta na perda de significação, ou seja, de sinais que antes davam forma ao todo.

Assim, ao prover o regresso ao todo, pela soma das partes, esse não mais constitui o que se tinha, pois, as integrações perdidas acarretam em um novo "todo", não sendo mais possível regressar ao estágio inicial (CAPRA, 2000; PEREIRA, 2002). Em outros termos, a soma das partes leva a um novo todo, e não ao todo original, antes da fragmentação, em detrimento da perda das interações entre as partes.

Morin (2005a) exemplifica esse processo. Ao extrair um chimpanzé (parte) de seu ambiente (todo) e o inserir em um novo habitat, enjaulado e sob cárcere privado, a análise desse "objeto" isolado tende a não permitir a apreensão de "aptidões e qualidades que se manifestam na vida social, afetiva e prática dos chimpanzés" (MORIN, 2005a, p. 102). Assim, analisar esse animal fora de seu ambiente (todo) traz, por si só, a perda de características que se estabelecem pela interação desse junto a outros animais e com o próprio ambiente.

Por essa limitação o paradigma holístico emerge como uma tentativa de abordar o todo, entretanto assumindo que há a segmentação das partes (WEIL, 1991; VERGARA, 1993) e, portanto, visa a complementação da teoria reducionista (CREMA, 1991). Essa complementação se dá pelo não isolamento do elemento para análise, permitindo assim que o processo analítico ocorra sobre a parte, estando esta, presente no todo de forma a manter as interações entre os elementos (PEREIRA, 2002).

Assim, por meio do reconhecimento da importância das integrações - representada pelo símbolo ' + ' na Figura 3 - entre os elementos, 0 holismo luta contra a mutilação das conexões (MORIN, 2005a) mantendo os elementos no todo, no caso dos chimpanzés em seu habitat natural, para análise. Esse paradigma visa a complementação da teoria reducionista por meio da síntese, que tende a permitir que se aborde 0 todo pelas partes (CREMA, 1991).

Condiz com a recontextualização dos elementos em um molde que contemple o todo (PEREIRA, 2002). Após a compreensão dessas partes, agora analisadas em seu contexto original, se assume que o todo é constituído pela soma dos resultados das partes, o que permite contemplar o todo pelo fato de não se perder as integrações entre os elementos (MARIOTTI, 2004; MORIN, 2005; MORIN, 2005a).

Por sua vez, a Teoria da Complexidade não assume a fragmentação, o que a distingue do paradigma cartesiano-newtoniano e holístico. Essa, em essência, visa o regressar da ciência para antes da seccionamento do todo em partes, para antes da perda das integrações entre os elementos (MORIN, 2005a). A ideia é contemplar o fenômeno em sua totalidade sem a particionar. 
No caso dos chimpanzés, não o remove do seu ambiente (reducionismo das partes para o todo) e nem promove a análise focada desse animal em seu ambiente (holismo do todo para as partes). A ideia é visualizar a complexidade presente entre o ambiente e o animal, entre o animal e o ambiente, esses inseridos em um todo que considera a natureza e o universo, pois tudo está junto e "se entrecruza, tudo se entrelaça para formar a unidade" (MORIN, 2005a, p. 188) e se transformam no uno, uma só coisa.

Em síntese, o paradigma cartesiano-newtoniano apresenta foco nas partes isoladas para o todo (letras $\mathrm{F}, \mathrm{E}, \mathrm{N}, \hat{\mathrm{O}}, \mathrm{M}, \mathrm{E}, \mathrm{N}$ e O) e mutila as conexões; o paradigma holístico apresenta foco no todo e analisa as partes dentro do todo mantendo suas conexões (letras $F, E, N, O \hat{O}, M, E, N$ e $\mathrm{O}$, considerando suas conexões, representadas pelo símbolo ' + '); e o complexo visualiza o todo e as partes, as partes e o todo, sem foco em um ou outro, pois tudo constitui o todo e o todo é constituído por tudo (palavra FENÔMENO em si). Diante dessas distinções o que se têm é a GC contemplada no antigo paradigma e ambicionada como necessária de ser abordada no paradigma holístico, sendo o posicionamento desse paradigma para com o conhecimento exposto na seção seguinte.

\section{A Gestão do Conhecimento holística}

A Gestão do Conhecimento (GC) é uma disciplina com aproximadamente 22 anos (BOLISANI; HANDZIC, 2015) e, como em outras áreas, assume em seu berço traços do paradigma cartesianonewtoniano. Tais traços estão atrelados ao fato da GC se orientar as organizações públicas e privadas de diversos segmentos, como tecnologia (PONS et al., 2014) e saúde (SALZANO et al., 2016) e, por consequência, absorve as características do campo da Administração, impregnado pelo reducionismo (SILVA, 2013; ANDRADE; AMBONI, 2017).

O reducionismo da Administração é visível na segmentação da empresa em organogramas, setores e áreas, pessoas especialistas e segmentadas em funções e cargos (FERREIRA, 2009). Pelo fato da GC se situar nesse contexto, naturalmente essa absorve essas fragmentações. Por um lado, sua própria distribuição é segmentada em áreas como liderança, equipe de GC disseminada em cargos e recursos físicos e financeiros (KUMAR; SINGH; HALEEM, 2015).

Por outro lado, para atingimento de seu intento de gerir o conhecimento a determinação de projetos pilotos (AKHAVAN; JAFARI; FATHIAN, 2006), por si só, assume a fragmentação organizacional como um imperativo para pôr em prática os projetos voltados ao conhecimento em menor escala, antes de sua promoção mais ampla na organização. Além do mais, o próprio conhecimento é fragmentado em diversos tipos, dentre eles o declarativo, processual, causa, relacional, básico, avançado e inovador (ZACK, 1999), tácito e explícito (NONAKA; TAKEUCHI, 1997) e implícito (NICKOLS, 2000; GRANT, 2007).

Além do campo da Administração, o campo tecnológico, pontuado por Vergara (1993) como sendo um dos contributos de Descartes e 
Newton para o mundo, não somente foi influenciado pelo reducionismo como também influencia fortemente a GC. Inicialmente, as investidas em GC tiveram foco estritamente tecnológico, objetivando a manutenibilidade do conhecimento do indivíduo na organização por meio de bases de conhecimento e outros recursos tecnológicos para acesso ao conhecimento empresarial (APO, 2013).

Acreditava-se que a tecnologia seria a solução, mas a negligência de aspectos humanos e outros aspectos organizacionais, como a cultura, culminou no fracasso destas inciativas (SNOWDEN, 2002). A lista de aspectos que conferem a influência do reducionismo na GC é tão longa quanto se queira tecê-la. Entretanto, o que resume essa forte influência cartesiana-newtoniana é o fato de que a GC opera sobre áreas e elementos já existentes e, por consequência, já fragmentados.

As pessoas, processos e tecnologias, dentre outros, são elementos presentes nas organizações e desenvolvidos sobre o alicerce do paradigma reducionista. Assim, a GC os remolda em estruturas voltadas ao conhecimento, influenciada por estudos com enfoque na Engenharia de Produção (SILVA, 2011), Administração (SILVA, 2015), Ciência da Informação (SILVA SEGUNDO; ARAÚJO; DUARTE, 2017), dentre outros.

Nesse momento, se assume que a GC é fragmentada e, como tal, a Teoria da Complexidade, que visa regressar para antes da fragmentação, tratando o todo pelas partes e as partes pelo todo em uma unidade única, não hierárquica e não reducionista (MORIN, 2005a) não se ajusta ao contexto organizacional no tempo presente. Entretanto, pesquisadores ponderam sobre a necessidade de posicionar a GC no paradigma holístico, cada qual argumentando sobre uma ótica para subsidiar essa orientação. Os achados desses estudos se embasam na análise de modelos de GC, também denominados frameworks ou estruturas, e evenciam a necessidade de se desenvolver proposta que contemplem a GC holisticamente.

Para os intentos dessa pesquisa, modelos são uma representação esquemática que elucida os elementos principais da GC e suas interfaces (HEISIG, 2009), tais como os propostos por Terra (2005), Pons et al. (2014) e Salzano et al. (2016). Conforme Cajueiro (2008, 102, p. 1) "Um modelo é a simplificação do mundo real, usada para demonstrar relacionamentos complexos em termos fáceis de serem entendidos." Portanto, tais modelos também são reducionistas, ou como diz Morin (2005a) simplificam a realidade, e são sobre 196 modelos de GC que Holsapple e Joshi (1999), Rubenstein-Montano et al. (2001), Heisig (2009) acenam a necessidade de uma abordagem holística para a GC.

Holsapple e Joshi (1999) analisaram 10 modelos de GC e concluíram que cada modelo possui elementos diferentes; no entanto nenhuma proposta anula a outra, conduzindo a necessidade de desenvolvimento de um modelo que seja abrangente e unificador (HOLSAPPLE; JOSHI, 1999). Rubenstein-Montano et al. (2001) estudaram 26 modelos e concluíram que, dentre as estruturas, há negligencia de aspectos da GC e não consenso sobre os elementos a serem considerados em um framework abrangente, bem como pontuou a necessidade de um modelo unificador. 
Posteriormente, Heisig (2009) examinou 160 modelos de GC de diversos países - registra-se a ausência de modelos brasileiros - e pontuou a busca pela homogeneidade em dimensões e processos de manipulação do conhecimento, bem como ponderou sobre a importância dos modelos para a sistematização dos esforços de GC. Por resultado, o estudo assinala o não consenso quanto a epistemologia do conhecimento nos modelos analisados, considera insuficientes os esforços em abordagens que contemplam elementos isolados e enfatiza a necessidade de uma abordagem holística.

Recentemente, Fteimi (2015) analisou 74 estudos de GC e os classificou de forma a representar qual o domínio dessa temática, contemplado por tais propostas. Por resultado, é proposto um esquema de classificação que compreende sete categorias e resume os fundamentos explorados pela academia acerca da GC. Dentre essas categorias é apresentada a holística, que demarca "diferentes elementos da GC, que devem ser considerados em conjunto" (FTEMI, 2015, p. 5, tradução do autor) nos frameworks, pois esses afetam a implementação da GC (FTEMI, 2015).

Por esses estudos, se estabelece a convergência de que a GC deve ser orientada para uma abordagem holística de forma a se atingir um modelo que seja unificador, orientado ao hólus da GC. Uma forma ponderada por estudiosos para atingimento do holístico é a colaboração entre as disciplinas para compreensão da totalidade (COIMBRA, 1996). Nesse contexto se tem a interdisciplinaridade como uma proposta de integração coordenada e cooperada entre as disciplinas e a transdisciplinaridade, que evoca tal integração com expressiva intensidade que não mais se torna possível a distinção dos limites entre as disciplinas (ALVARENGA; SOMMERMAN; ALVAREZ, 2005).

O estudo desenvolvido por Scholl et al. (2004) junto a 45 especialistas abordou o futuro da GC e evidenciou que estudos inter e transdisciplinares seriam benéficos uma vez que a GC é um campo "altamente estimado em pesquisa e prática, mas ao mesmo tempo relativamente difuso e disperso em conceitos divergentes, perspectivas e disciplinas" (SCHOLL et al., 2004, p. 19, tradução do autor). Corroborando com Scholl et al. (2004), Lloria (2008) afirma que cada campo de pesquisa fornece importantes informações sobre um aspecto da GC, mas nenhum campo individualmente traduz uma estrutura (modelo) integrador, sendo necessários estudos transdisciplinares.

Heisig (2009) também sinaliza que a pesquisa e prática em GC é também impulsionada pela cooperação entre as disciplinas. Para Bernstein (2014) a interdisciplinaridade voltada para estudos relacionados a epistemologia do conhecimento tenderia a obtenção de uma nova unidade que permitiria contemplar o conhecimento em sua totalidade. Heisig (2015), mediante a 222 respondentes de 42 nacionalidades, oriundos de 38 países, revelou a interdisciplinaridade como abordagem teórica para 0 avanço da GC, corroborando com os achados de Scholl et al. (2004) e Heisig (2009), assinalando ser uma perspectiva ainda ambicionada. 
Tais proposições evidenciam esforços a serem empregados no campo da GC rumo ao holístico. Em resgate ao que se considera por holístico (reveja o Quadro 1 ), se tem a luta contra a fragmentação resultante do reducionismo (MORIN, 2005a), pois essa fragmentação se faz presente uma vez que o holismo não exclui o paradigma cartesianonewtoniano (VERGARA, 1993; PEREIRA, 2002), a orientação do todo sobre as partes (MORIN, 2005a) como sendo uma tendência do reducionismo reverso (o original é das partes para o todo) e a hierarquia de um supra sistema sobre o sistema, esse constituído por subsistemas (MARIOTTI, 2004).

Ante ao delineamento que constitui o paradigma holístico, fundamentado nos autores supracitados, e perante a necessidade de abordar o hólus no âmbito das tratativas que visam gerir o conhecimento, a GC holística pode, então, ser conceituada como: uma proposta que visa abordar as partes pelo todo, considerando que essas partes não devem ser analisadas de forma isolada por haver uma interligação entre essas e, portanto, resulta em recontextualizar essas partes num molde que contemple a totalidade.

Assim, uma abordagem holística da GC não somente remete a contemplar todas as áreas que a constituem, mas consiste em contemplar tais áreas assumindo que essas se relacionam e, portanto, devem ser analisadas dentro de seu contexto para que as interligações entre essas mantenham suas propriedades.

\section{Considerações finais}

A GC é um campo fragmentado, imbricado pelo paradigma reducionista. Isso se deve ao fato de atuar em organizações que são, historicamente, fracionadas em estruturas, setores e cargos. Também pela própria estrutura da GC, seccionada em áreas como tecnologia, pessoas, processos, programas pilotos, dentre outros. Todavia, há indícios representativos da necessidade de posicionar esse campo científico nos moldes do paradigma holístico.

Mediante a essa necessidade e devido a constatação de que interpretações errôneas a cerca desse termo tem se proliferado e esforços para clarear seu significado são bem-vindos, esse texto perpassou sobre esse paradigma o distinguindo de outros. Para isso, foi necessária uma regressão histórica sobre o paradigma cartesiano-newtoniano (reducionista), reinante até os dias atuais. Após essa regressão, outras abordagens como a TGS, SACs e Teoria de Complexidade foram expostas de forma as distinguir do holismo. Feito esse delineamento, um conceito da GC holística foi exposto, visando municiar pesquisa futuras em GC de forma com que essas se atentem ao que se considera por holístico na GC. Em outros termos, não é somente abordar a empresas em sua totalidade, mas também prover estudos considerando cada uma das partes em seu contexto para que as conexões com as demais sejam mantidas.

Por limitação, esse estudo não apresentou indícios que revelem se a GC está caminhando para uma abordagem holística, haja vista que essa 
tem sido apontada como um caminho a ser trilhado. Assim, essa é uma sugestão de pesquisa futura. Todavia, antes dessa análise, outra questão emerge: quais as partes que constituem uma GC holística? Ambas as interrogativas são sugeridas como pesquisas futuras, sendo esses objetivos de estudos futuros a serem desenvolvidos pelo autor dessa pesquisa.

Agradecimentos à FAPEMIG, à CAPES, ao CNPq e à FUMEC.

\section{REFERÊNCIAS}

AKHAVAN, P.; JAFARI, M.; FATHIAN, M. Critical success factors of knowledge management systems: A multi-case analysis. European Business Review, v.18, n. 2, p. 97-113, 2006.

ALVARENGA, A. T.; SOMMERMAN, A.; ALVAREZ, A. M. S. Congressos internacionais sobre transdisciplinaridade: reflexões sobre emergências e convergências de idéias e ideais na direção de uma nova ciência moderna. Saúde e Sociedade, v. 14, n. 3, p. 9-29, 2005.

ANDRADE, R.; AMBONI, N. TGA - Teoria Geral da Administração. Elsevier Brasil, 2017 [livro eletrônico].

APO - ASIAN PRODUCTIVITY ORGANIZATION. Knowledge management for public-sector, 2013. Japão: Asian Productivity Organization, 2016.

BEHRENS, M. A. A prática pedagógica e o desafio do paradigma emergente. Revista Brasileira de Estudos Pedagógicos, v. 80, n. 196, p. 383-403, 2007.

BERNSTEIN, J. H. Disciplinarity and transdisciplinarity in the study of knowledge. Informing Science. The International Journal of an Emerging Transdiscipline, v. 17, p. 241-273, 2014.

BERTALANFFY, L. V. The history and status of general systems theory. Academy of Management Journal, v. 15, n. 4, p. 407-426, 1972.

BOLISANI, E.; HANDZIC, M. (Ed.). Advances in knowledge management: celebrating twenty years of research and practice. Springer, 2015.

CAJUEIRO, J. L. G. Modelo de gestão do conhecimento para instituições de ensino superior. 2008. 152f. Tese (Doutorado em Engenharia de Produção) -. Programa de Pós-graduação em Engenharia de Produção, UFPE, 2008.

CAPRA, F. A teia da vida: uma nova compreensão científica dos sistemas vivos. 9 ed. São Paulo: Cultrix, 2000.

COIMBRA, J. Á. A. Considerações sobre a Interdisciplinaridade. USP: Interdisciplinaridade em Ciências Ambiental, p. 52-70,1996.

CREMA, R. Abordagem holística: integração do método analítico e sintético. In: BRANDÃO, D.; CREMA, R. (orgs). O novo paradigma holístico: ciência, filosofia, arte e mística. São Paulo: Summus, p. 83-99, 1991. 
CREMA, R. Introdução à visão holística: breve relato de viagem do velho ao novo paradigma. 6 ed. São Paulo: Summus, 2015 [livro eletrônico].

FARRER, H. et al. Programação estruturada de computadores: algoritmos estruturados. 3. ed, Rio de Janeiro: LTC, 2009.

FLACH, C. R. C.; BEHRENS, M. A. Paradigmas educacionais e sua influência na prática pedagógica. In: CONGRESSO NACIONAL DE EDUCAÇÃO, 2008, Curitiba. [Anais...] Curitiba: PUC-PR, 2008.

FTEIMI, N. Analyzing the literature on knowledge management frameworks: Towards a normative knowledge management classification schema. In: EUROPEAN CONFERENCE ON INFORMATION SYSTEMS, 23, 2015. [Proceedings...], 2015. p. 1-17.

GRANT, K. A. Tacit knowledge revisited - we can still learn from Polanyi. The Electronic Journal of Knowledge Management, Sonning Common, UK, nv. 5, n. 2, p. 173-180, 2007.

HEISIG, P. Future research in knowledge management: results from the global knowledge research network study. In: BOLISANI, E.; HANDZIC, M. (Eds). Advances in knowledge management: celebrating twenty years of research and practice. Berlin :Springer, p. 151-182, 2015.

HEISIG, P. Harmonisation of knowledge management - comparing $160 \mathrm{KM}$ frameworks around the globe. Journal of knowledge management, v. 13, n. 4, p. 4-31, 2009.

HOLSAPPLE, C. W.; JOSHI, K. D. Description and analysis of existing knowledge management frameworks. In: ANNUAL HAWAII INTERNATIONAL CONFERENCE ON SYSTEMS SCIENCES, 32, 1999. [Proccedings...]. IEEE Computer Society, p. 15, 1999.

KUHN, T. S. A estrutura das revoluções científicas. 5.ed. São Paulo: Perspectiva, 1998.

KUMAR, S.; SINGH, V.; HALEEM, A. Critical success factors of knowledge management: modelling and comparison using various techniques. International Journal of Industrial and Systems Engineering, v.21, n. 2, p. 180-206, 2015.

LLORIA, M. B. A review of the main approaches to knowledge management. Knowledge Management Research \& Practice, v. 6, n. 1, p. 77-89, 2008.

MACIEL, C.; SILVA, A. Gerenciando pessoas utilizando modelos holísticos. Revista da Administração Contemporânea - RAC, v. 12, n. 1, p. 35-58, 2008.

MARIOTTI, H. Reducionismo, holismo, pensamento sistêmico e complexo (suas consequências na vida cotidiana) In: RÖSING, T. M. K.; FALCI, N. M. (Orgs). Edgar Morin: religando fronteiras. Universidade de Passo Fundo, p. 59-72, 2004. 
MCELROY, M. W. The new knowledge management.Burlington : Butterworth-Heinemann, 2003.

MORIN, E. Ciência com consciência. 8. ed. Rio de Janeiro: Bertrand, 2005a.

MORIN, E. Introdução ao pensamento complexo. Porto Alegre: Sulina, 2005.

NICKOLS, $\mathrm{F}$. The knowledge in knowledge management. In: WOODS, J. A.; CORTADA, J. The Knowledge Management Yearbook 2000-2001. Boston: Butterworth-Heinemann, 2000. p. 12-21.

NONAKA, I.; TAKEUCHI, H. Criação de conhecimento na empresa. 10 ed. Rio de Janeiro: Campus, 1997.

PEREIRA, M. F. A gestão organizacional em busca do comportamento holístico. In: ANGELONI, M. T. (Org.). Organizações do conhecimento: infra-estrutura, pessoas e tecnologia. São Paulo: Saraiva, 2002. p.2-28.

PICKERING, W. A. Sistemas adaptativos complexos: lingua(gem) e aprendizagem. Campinas, Trabalhos em Linguística Aplicada, v. 51 n. 2, jul.dez. 2012.

PONS, N. L. et al. Design of a knowledge management model for improving the development of computer projects' teams. Revista Espanola de Documentacion Cientifica, v. 37, n. 2, 2014.

RUBENSTEIN-MONTANO, B. et al. A systems thinking framework for knowledge management. Decision support systems, v.31, n. 1, p. 5-16, 2001.

SALZANO, K. et al. A Knowledge management framework and approach for clinical development. Therapeutic Innovation \& Regulatory Science, v. 50, n. 5, p. 536-545, 2016.

SANTOS, L. M. L.; PELOSI, E. M.; OLIVEIRA, B. C. S. C. M. O. Teoria da Complexidade e as múltiplas abordagens para compreender a realidade social. Serviço Social em Revista, Londrina, v. 14, n. 2, p. 47-72, 2012.

SCHOLL, W. et al. The future of knowledge management: an international delphi study. Journal of Knowledge Management, v. 8, n. 2, p. 19-35, 2004.

SILVA SEGUNDO, S.; ARAÚJO, W. J.; DUARTE, E. N. Gestão do conhecimento organizacional: estudo aplicado à biblioteca virtual Paul Otlet. Informatio. Revista del Instituto de Información de la Facultad de Información y Comunicación, v. 22, n.1, p. 26 - 42, 2017.

SILVA, A. B.; REBELO, L. M. B. As Implicações do pensamento complexo na análise organizacional. In : ENCONTRO ANPAD, 31, 2007, Rio de Janeiro. [Anais...] Rio de Janeiro : ANPAD, 2007. p.1-16.

SILVA, C. R. M. Gestão do conhecimento com foco na segurança do paciente: proposta de um modelo de gestão para hospitais. 2015, $101 \mathrm{f}$. Dissertação (Mestrado em Administração - Gestão em Sistemas de Saúde) 
- Programa de Mestrado Profissional em Administração - UNINOVE, São Paulo, 2015.

SILVA, R. O. Teorias da administração. 2.ed. São Paulo: Pearson Education do Brasil, 2013.

SILVA, R. S. G. Proposta de diretrizes para o desenvolvimento da gestão do conhecimento por meio de comunidades de prática. 2011, 103 f. Dissertação (Mestrado em Engenharia de Produção) - Programa de Mestrado em Engenharia de Produção, USP, São Carlos, 2011.

SNOWDEN, D. Complex acts of knowing: paradox and descriptive selfawareness. Journal of Knowledge Management, v. 6, n. 2, p. 100-111, 2002.

SOMMERMAN, A. A inter e a transdisciplinaridade. In: SEMINÁRIO INTERNACIONAL DE EDUCAÇÃO, 10, 2005. [Interdisciplinaridade como forma de inclusão numa educação mundial]. Cachoeira do Sul, ULBRA, 2005. p.1-20.

STACEY, R. Emerging strategies for a chaotic environment. Long Range Planning, v. 29, n. 2, p. 182-189, 1996.

TERRA, J. C. C. Gestão do conhecimento: o grande desafio empresarial. 5ed. Rio de Janeiro: Elsevier, 2005.

VERGARA, S. C. Sobre a intuição na tomada de decisão. Rio de Janeiro : FGV, 1993. (Cadernos EBAP,62). 61p.

WEIL, P. O novo paradigma holístico: ondas a procura do mar. In: BRANDÃO, D.; CREMA, R. (Orgs). O novo paradigma holístico: ciência, filosofia, arte e mística. São Paulo: Summus, 1991. p. 14-38.

ZACK, M. H. Developing a knowledge strategy. California Management Review, v. 41, n. 3, p. 125-145, 1999.

ZIVIANI, N. Projeto de algoritmos com implementações em Pascal e C. 3. ed. São Pauo : Cengage Learning, 2014. 644p. 